\title{
AS HABILIDADES DOS GESTORES ESPORTIVOS: UM ESTUDO DE CASO EM NOVO HAMBURGO
}

\author{
THE SPORTS MANAGERS' SKILLS: A \\ CASE STUDY IN NOVO HAMBURGO
}

Jefferson Dobner Sordi ${ }^{1}$

Raquel Rejane Theobald ${ }^{2}$

Recebido em: 21 de janeiro de 2017

Aprovado em: 08 de maio de 2017

Sistema de Avaliação: Double Blind Review

RGD |v. 14 |n. 2 | p. 141-154 |jul./dez. 2017

\begin{abstract}
RESUMO
O esporte está presente na sociedade por meio das organizações esportivas, que prestam serviços para clientes, praticantes e atletas, além de empregar profissionais e treinadores. Os gestores dessas organizações fazem parte de uma área em fase de consolidação, tanto profissional quanto acadêmica. Esses profissionais apresentam como característica principal a multidisciplinaridade de conhecimentos, necessários para o exercício de suas atividades. Como são, em sua maioria, graduados em cursos de Educação Física, os gestores esportivos tendem a apresentar dificuldades, no entanto, em determinadas disciplinas próprias da Administração, que são as duas principais áreas de conhecimento exigidas no exercício da gestão esportiva. Nesse sentido, o presente trabalho tem como objetivo analisar quais são as ofertas de organizações esportivas e avaliar quais são as principais necessidades para o desenvolvimento de habilidades de gestão esportiva, considerando um grupo de administradores esportivos de Novo Hamburgo, na região metropolitana de Porto Alegre, no Rio Grande do Sul. Para tanto, foram selecionadas dez organizações e gestores esportivos para um estudo de casos múltiplos. Por meio de entrevistas, análise de conteúdo e contagem, foi possível perceber que os gestores esportivos analisados já ofertam muitos pontos essenciais para a administração de uma organização esportiva, como relacionamento com clientes e planejamento estratégico. Percebeu-se, porém, que há um grupo de habilidades ainda a desenvolver, especialmente no que diz respeito àquelas relacionadas ao marketing, finanças e recursos humanos. Isso se dá devido à oferta enxuta de tais conceitos na formação acadêmica dos gestores analisados, que se concentra, majoritariamente, na Educação Física.
\end{abstract}

Palavras-chave: Gestor Esportivo. Perfil. Habilidades. Conhecimentos.

\begin{abstract}
Sport is present in society through sports organizations that provide services to clients, practitioners, athletes, and also employed professionals and coaches. The managers of this organizations are part of an area undergoing consolidation in Brazil, both professionally and academically. These professionals present as main characteristic the multidisciplinary of knowledge necessary for the exercise of their activities. Normally graduated in Physical Education courses, the sport managers tend to present difficulties in certain disciplines of the Business field, that are the two majors knowledge fields in sports management. In this sense, the present work's aim to analyze what are the sports organization offers and evaluate what are the main development needs of sports management skills in a sport managers group of Novo Hamburgo city, in the metropolitan region of Porto Alegre, Rio Grande do Sul, Brazil. Ten selected organizations and sport managers are designated for a multi-case study. Through interviews, content analysis and counting it was possible to perceive that the analyzed sports managers already offer many essential points for the administration of a sports organization, like relationship marketing and strategic plans, but that there is a group of abilities still to develop, especially with regard to those related

\footnotetext{
${ }^{1}$ Doutorando em Administração (Pontifícia Universidade Católica do Rio Grande do Sul/Brasil). Professor na Universidade Feevale (Novo Hamburgo/Brasil). E-mail: jefferson@feevale.br.

${ }^{2}$ Mestranda em Administração (Universidade de Santa Cruz do Sul/Brasil). E-mail: raquelrtheobald@ gmail.com.
} 
to marketing, finance and human resources, results of a lack in the academic formation of the sports management analyzed, which is concentrate almost in its entirety in Physical Education.

Keywords: Sports Manager. Profile. Skills. Knowledge.

\section{INTRODUÇÃO}

O esporte está presente diariamente na sociedade, por meio de diferentes estabelecimentos, que oportunizam o acesso às mais variadas práticas físicas e esportivas, visando atender às necessidades e desejos daqueles que se interessam. A partir da oferta de atividades físicas através das Organizações Esportivas, o esporte passou a estar mais presente na vida das pessoas. Grande parte da população, de diferentes regiões e comunidades, procura as Organizações Esportivas por diversos motivos. Estabelecimentos como academias, clubes e escolas, com foco na prática esportiva, oferecem seus serviços a variados públicos. Esses estabelecimentos propõem, em sua prática, colocar o corpo em movimento, pois tem por objetivo oferecer saúde, estética, lazer e até mesmo atividades de descontração aos seus públicos.

A presença do esporte na atualidade é comumente associada à sua participação na sociedade, com seu papel de inclusão de milhares de pessoas (MORGAN; SUMMERS, 2008). É extremamente necessário que as pessoas que administram as organizações esportivas possam fazê-lo de forma competente, a fim de perpetuá-las. Essas pessoas responsáveis pelo desenvolvimento das empresas voltadas ao esporte são os gestores esportivos.

A própria gestão esportiva, dentro do contexto brasileiro, é uma área que está em consolidação (ROCHA; BASTOS, 2011). Chelladurai (2009) comenta que os primeiros cursos voltados ao sport managent datam da década de 60. Em um levantamento de 2009, Masteralexis, Barr e Hums (2009) afirmam que mais de 300 universidades americanas oferecem programas de gestão do esporte em nível de bacharelado, mestrado e/ou doutorado. A título de comparação, no Brasil, Mazzei, Amaya e Bastos (2013) identificaram 43 opções de cursos de formação para gestores esportivos.

Essa escassez de oferta brasileira, se comparada à americana, levanta dúvidas em relação à formação dos gestores esportivos. Como os profissionais da área têm sido formados? Em quais cursos e qual modelo de currículo é abordado nesses cursos? Quais disciplinas da área estão presentes na formação do profissional? Além disso, é necessário um olhar de duplo sentido para os gestores esportivos: de um lado a sua formação, e de outro, seu aprimoramento como profissional que atuará em organizações esportivas (BASTOS et al., 2006).

Nesse sentido, o presente trabalho tem como objetivo analisar a realidade local, da cidade de Novo Hamburgo, considerando um grupo de gestores esportivos, investigando suas ofertas de serviços e suas necessidades de desenvolvimento conceitual, no que diz respeito aos aspectos de gestão de uma organização esportiva. Para tanto, optou-se por uma estratégia de estudo de caso, analisando dez gestores esportivos. Mais do que tentar estabelecer um perfil para eles, como feito por outros trabalhos (AMARAL; BASTOS, 2015; AMARAL, 2015; BARROS et al., 2013), o presente estudo se justifica pela abordagem, cujo foco é às necessidades de desenvolvimento dos gestores esportivos. Para tanto, serão utilizados os conceitos de Parkhouse (2004), que desenvolveu um grupo de habilidades de um gestor competitivo.

O artigo divide-se, além dessa introdução, em outras quatro partes: a fundamentação teórica, que aborda o papel do esporte na sociedade, a gestão esportiva e o papel do gestor esportivo; o método de pesquisa; a análise e discussão dos resultados e as considerações finais, bem como limitações e novas oportunidades de pesquisa. 


\section{FUNDAMENTAÇÃO TEÓRICA}

Para atender ao objetivo proposto nesse trabalho, faz-se importante recuperar e apresentar os componentes teóricos mais pertinentes a ele. Opta-se pela separação deste referencial em três grandes seções. Na primeira, discute-se o papel do esporte dentro da sociedade em que ele se insere. Posteriormente, o tema de gestão do esporte é debatido, apresentando um breve panorama de sua pesquisa. Por fim, as atenções recaem sobre o gestor esportivo, observando as pesquisas que tratem da formação do seu perfil.

\subsection{ESPORTE E SOCIEDADE}

Atualmente, é difícil fazer referência ao esporte sem pensar em como se dá a sua participação na sociedade. Morgan e Summers (2008) destacam que o esporte, em todas as suas manifestações, envolve milhares de pessoas e também muito dinheiro no mundo todo. O esporte está presente na vida do homem e contribui para o desenvolvimento esportivo individual e social nas comunidades. Segundo Lucena (2001), a sociedade vê no esporte uma forma de manifestação, visto que o cidadão que vive na cidade vive também o esporte. $\mathrm{E}$ a cidade passa a ser um espaço de manifestações.

O esporte em uma sociedade foi definido por Helal (1997) como qualquer atividade física subordinada a uma organização ou a ações que envolvam uma brincadeira ou o prazer de participantes. Já Steinhilber (1996) complementa o quanto o esporte cresceu na sociedade. “[...] há um comprovado aumento do interesse por atividades físicas e exercícios físicos, sejam caminhadas, excursões, práticas esportivas não formais, corridas e outras formas que são muitas vezes denominadas esportes" (STEINHILBER, 1996, p. 95).

A partir destas opiniões e acompanhando a evolução do esporte, percebe-se que as mais diversas modalidades de atividade física tornaram-se produtos de consumo, atingindo um grande público através dos meios de comunicação. Com a ajuda da mídia, a prática esportiva acaba possibilitando a difusão de ideias sobre cultura corporal do movimento, informando sobre diversas práticas corporais e de saúde, destacando-se, mais frequentemente, em revistas, jornais ou noticiários (BETTI, 1998).

Com a inserção do esporte no dia a dia da população, percebe-se que a prática esportiva se tornou fator social contribuinte para a comunidade. Em consequência disso, houve um aumento da procura por estabelecimentos que ofereçam serviços de prática esportiva. Recuperando o exposto por Helal (1997), o esporte, como atividade física, deve estar vinculado a uma organização. Tais instituições são existem em função da própria atividade física, esportiva e de lazer. Constituem-se como organizações esportivas os centros de treinamento e escolinhas de modalidades esportivas, academias voltadas para a atividade física e/ou esportiva, clubes e associações exclusivamente esportivos. Ainda como exemplos, empresas de consultoria e assessoria em negócios esportivos, de lazer e recreação fazem parte desse grupo, assim como ligas, federações, confederações esportivas e ainda outras entidades voltadas para o esporte. (REZENDE, 2000, p. 47). Do ponto de vista administrativo, as organizações esportivas, de modo geral, são instituições que devem ser geridas de forma competente para maior benefício de seus consumidores. Por isso, a seção seguinte tem como objetivo entender a gestão esportiva como uma área de investigação.

\subsection{GESTÃO ESPORTIVA}

A gestão esportiva já pode ser considerada uma ciência consolidada no Brasil (MAZZEI; AMAYA; BASTOS, 2013) e entende-se como sendo a aplicação dos principais conceitos e teorias do 
campo da Administração a todas as formas de manifestação do fenômeno esportivo que são desempenhados na sociedade atual (MAZZEI; BASTOS, 2012). Essa ampla área de atuação faz com que a gestão esportiva seja encarada como uma ciência multidisciplinar, derivadas de relações complexas (PIRES; SARMENTO LOPES, 2001; GAYA, 2008). Complementa essa ideia a própria definição estabelecida pela North American Society for Sport Management (Sociedade Norte Americana para Gerência do Esporte - NASSM), que define a gestão esportiva como:

[...] um agrupamento interdisciplinar, que tem como características a ênfase nos temas; direção, liderança e organização esportiva, incluindo questões comportamentais, ética, marketing, comunicação, finanças, economia, responsabilidade social, legislação e preparação profissional. (NOLASCO et al., 2005, p. 760).

Da Costa (2005) remonta para a década de 1920 como a origem da gestão do desporto nacional, quando menciona que a Escola de Educação Física do Exército, quando da elaboração de seus manuais sobre as instalações esportivas, foi uma das primeiras a criar instrumentos que hoje poderiam ser entendidos como forma de gerir aquele patrimônio da melhor forma possível. Em 1939, com a criação da Escola Nacional de Educação Física na Universidade Federal do Rio de Janeiro, a disciplina de Administração Esportiva entrou no currículo de formação dos profissionais de Educação Física.

A gestão esportiva, no entanto, diferencia-se de sobremaneira do "badalado" marketing esportivo (ROCHA; BASTOS, 2011). As atividades de marketing são consideradas uma parte das atribuições da gestão, que envolve a coordenação das etapas de produção, entendida como a transformação da matériaprima em produto final, e do marketing. Utilizando uma definição mais clara, a "gestão do esporte é o processo de trabalhar com pessoas e recursos materiais para realizar objetivos de organizações esportivas, de maneira eficaz" (ROCHA; BASTOS, 2011, p. 94). Chelladurai (2009) destaca que a gestão esportiva trata da coordenação das atividades de marketing e produção de uma organização esportiva, para que os serviços prestados aos participantes e espectadores possam ser atendidos da melhor forma possível.

As organizações esportivas são aquelas que existem em função da atividade física, esportiva e de lazer, tais como centros de treinamento e escolinhas de modalidades esportivas. Além delas, são consideradas nessa classificação as academias voltadas para a atividade física e/ou esportiva, clubes e associações exclusivamente esportivos e ainda as consultorias e assessorias em negócios esportivos, de lazer e recreação, assim como ligas, federações, confederações esportivas e ainda outras entidades voltadas para o esporte. (REZENDE, 2000).

Mullin, Hardy e Sutton (1993) comentam que as funções de planejamento, organização, direção e controle dentro do contexto de uma organização, cujo objetivo primário são atividades esportivas, pode ser caracterizado como gestão esportiva. Nesse sentido, Parkhouse (2004) sustenta que a combinação de esportes e gestão compreende de forma contemporânea a gestão esportiva (ZOUAIN; PIMENTA, 2006).

De acordo com Parks, Zanger e Quarterman (1998), existem dois aspectos relevantes dentro do contexto da gestão esportiva. Primeiro, é possível observá-la como uma área profissional, onde as pessoas trocam o trabalho pela remuneração. Segundo, é possível percebê-la como uma área acadêmica, cuja responsabilidade é a preparação do profissional e acontece em muitas instituições de ensino superior. Apesar de atrelada aos cursos de Administração, a gestão esportiva dentro do Brasil é ocupada por profissionais de educação física, alinhando falta de formação teórica mais específica sobre aspectos da gestão (VIEIRA; STUCCHI, 2007). Complementando a ideia, Mazzei e Bastos (2012), relatam que existe um apelo recente dos próprios envolvidos das organizações esportivas (atletas, praticantes, 
treinadores, patrocinadores e demais consumidores) para que se aumente a qualidade da gestão dessas organizações, isto sendo comprovado pelo anseio do conhecimento maior na área da gestão esportiva.

\subsection{O GESTOR ESPORTIVO}

A pesquisa acadêmica envolvendo os gestores esportivos, seu perfil e suas práticas, ainda é escassa, especialmente aplicando-se ao contexto brasileiro (BARROS FILHO et al., 2013). Dentre os materiais publicados, é possível extrair algumas características e fundamentos necessários para explicar e tentar estabelecer um perfil genérico de um gestor das organizações esportivas. Um desses trabalhos é o de Celma (2000), que define como capacidades dos gestores esportivos modernos a de conjugar políticas, definir a missão do serviço que irá prestar, alinhando conhecimentos administrativos, aplicando técnicas de marketing e comunicações. A interdisciplinaridade do cargo fez Gasca (2000) afirmar que a constante atualização e melhoria de habilidades são necessárias.

Parkhouse (2004) comenta que a carreira de um gestor esportivo é fundamentada em cursos de graduação e especialização, tendo como dois pilares de sustentação: a Educação Física e a Administração. Essas duas bases refletem as características e responsabilidades dos gestores, conforme menciona Parks, Zanger e Quarterman (1998). Os autores comentam que as atribuições e atividades dos gestores esportivos são divididas em quatro grandes agrupamentos: atividades de gerência geral; gerência organizacional; gestão de informações; e ciências do esporte e exercício. Os quatro apresentam características de interdependência e interligação, com as atividades de gerência geral, como as responsabilidades que todos os gestores esportivos devem dominar. É importante ressaltar, também, que Parks, Zanger e Quarterman (1998) identificam que as habilidades são, em alguns casos, transferíveis para que outras pessoas possam desempenhar a função.

No sentido de ampliar as habilidades e competências de um gestor esportivo, Parkhouse (2004) detalhou-as. Para o autor, os gestores esportivos devem ter habilidades básicas, que no seu entendimento, deveriam estar presentes em todos os profissionais, e compreendem a oratória, a redação, a familiaridade com a computação, além de conhecimento organizacional e matemático. $\mathrm{O}$ autor sublinha que a liderança e a capacidade de negociação não podem ser desconsideradas. Além das básicas, os gestores devem ter habilidades de comunicação, integrando a redação e o discurso de forma clara. O marketing e as vendas, compreendendo a promoção de ideias, buscando o consumidor ideal para suas organizações, compreendem mais uma das habilidades descritas por Parkhouse (2004). Outro grupo de capacidades tem relação com a supervisão e gestão de recursos humanos, fortalecendo a equipe de trabalho para que se alcancem os objetivos com mais harmonia. O penúltimo grupo de habilidades descritas pelo autor diz respeito às instalações esportivas, tendo como objetivo principal o olhar sobre o todo da organização, no intuito de agradar aos clientes, objetivando lucro. Por fim, os aspectos fiscais e financeiros da organização são habilidades que os gestores esportivos devem possuir para que possam planejar e controlar os demonstrativos contábeis e financeiros da organização.

Os estudos presentes na literatura apresentam um gestor esportivo como um profissional que possui poder de decisões em suas entidades, mas que tende a falhar em obter uma visão ampla do negócio, optando por uma administração centrada na rentabilidade da organização. Desse modo, o presente artigo tem por objetivo demonstrar no contexto da cidade de Novo Hamburgo, no Rio Grande do Sul, quais as habilidades dos gestores esportivos e se os mesmos se preocupam em sanar esses problemas em suas organizações. No próximo capítulo, apresenta-se a metodologia desenvolvida a fim de alcançar esse objetivo. 


\section{MÉTODO}

Para atender ao objetivo desse artigo, optou-se por uma pesquisa descritiva e qualitativa, tendo como técnicas de coleta de dados entrevistas e questionários. O estudo buscou descrever características de organizações, levantando opiniões, atitudes e crenças de uma população (GIL, 2002). Diante dessa perspectiva, vale destacar as considerações de Prodanov e Freitas (2013, p. 52) a respeito da pesquisa descritiva: "quando o pesquisador apenas registra e descreve os fatos observados sem interferir neles". Os autores ressaltam ainda que o objetivo desse tipo de pesquisa é descrever as características da população, fenômeno ou o estabelecimento de relações entre variáveis.

Definiu-se como procedimentos a pesquisa bibliográfica e o estudo de caso. O estudo de caso consiste em uma investigação empírica sobre um fenômeno contemporâneo, inserido em um contexto de vida real (WOODSIE; WILSON, 2003). A técnica permite a coleta de dados múltiplos, como entrevistas, observações e outros tipos de materiais, tendo como objetivos prover descrições ou gerar teorias (EISENHARDT, 1989).

Durante o mês de abril de 2015, participaram deste estudo proprietários de Organizações Esportivas responsáveis pelos encaminhamentos estratégicos da empresa e pela tomada de decisão. Suas empresas estão situadas na cidade de Novo Hamburgo, Rio Grande do Sul. Optou-se por selecionar dez empresas do ramo esportivo, que foram entrevistadas pessoalmente, por meio de entrevista padronizada/estruturada. Essas empresas prestam serviços na área esportiva, atuando em diversos ramos de negócios, como academias, clubes, escolas de natação, escolas de dança, escola de lutas, estúdios de pilates, entre outros. Considerando essa técnica de entrevista, realizada com proprietários das empresas, o estudo caracteriza-se como qualitativo, tratando-se de um ambiente natural, sendo a fonte direta para coleta de dados, em que o pesquisador é o instrumento-chave (PRODANOV; FREITAS, 2013).

A partir de um contato telefônico com o proprietário, foi agendado um horário de forma que fosse possível uma conversa pessoalmente. Nesse momento também se realizou uma breve apresentação pessoal, esclarecimento dos objetivos do presente estudo e confiabilidade das informações. A coleta procurou atender ao que os autores Prodanov e Freitas (2013) orientam, optando pela entrevista realizada face a face (entrevistador mais entrevistado). Os pesquisadores apontam ainda para o conteúdo da entrevista, "que pode ou não ser realizada com base em um roteiro de questões preestabelecidas e até mesmo impressas." (PRODANOV; FREITAS, 2013, p. 106). Sendo assim, a entrevista abordou questionamentos a respeito da formação pessoal do gestor e das necessidades administrativas encaradas pelas empresas.

A análise dos dados resultantes das entrevistas foi feita através do seu conteúdo, usando como uma das técnicas a contagem e posterior codificação das mensagens em categorias (BARDIN, 2009). A contagem das informações obtidas na coleta de dados tem caráter autônomo (HANNAH; LAUTSCH, 2011), uma vez que os números produzidos pela contagem são suficientes para as análises, pois se cria um sumário daquilo que foi coletado no campo. A contagem complementa extratos das entrevistas, condensadas em tabelas de reforço (LANGLEY; ABDALLAH, 2011), que são apresentadas durante a discussão dos achados. As principais necessidades de aprimoramento foram cruzadas com as habilidades de Parkhouse (2004), possibilitando observar os principais pontos de melhorias para os gestores esportivos entrevistados.

Acredita-se que através da metodologia proposta foi possível perceber características e entender encaminhamentos administrativos realizados por parte das empresas entrevistadas, de forma a cruzar estes dados na busca por atender ao objetivo do presente estudo. 


\section{RESULTADOS E DISCUSSÃO}

Esse capítulo tem duas abordagens na tentativa de atingir o objetivo da pesquisa que é entender a oferta e necessidades de aprimoramento e desenvolvimento de um grupo de gestores esportivos da cidade de Novo Hamburgo. Nesse sentido, há um primeiro foco na apresentação das organizações esportivas e seus gestores, para, em um segundo momento, abordar suas necessidades de desenvolvimento como gestores.

Cabe ressaltar que, quando pertinente, as Organizações Esportivas serão identificadas pelas letras de "A" a "J", representando as dez empresas entrevistadas. Considerando as empresas por ramo específico, as dez organizações esportivas entrevistadas classificam-se como: seis academias, uma escola de dança e três estúdios de pilates. Na tabela 1, apresenta-se o retorno quanto à identificação da empresa por ramo de atividade, questões sobre as modalidades oferecidas, quantidade de funcionários e quantidade de alunos, informações estas que representam as características gerais das Organizações Esportivas entrevistadas.

Tabela 1 - Dados das Organizações Analisadas

\begin{tabular}{|c|c|c|c|c|}
\hline $\begin{array}{l}\text { Organização } \\
\text { Esportiva }\end{array}$ & Ramo & Modalidades Oferecidas & $\begin{array}{c}\text { Quantidade } \\
\text { de } \\
\text { Funcionários }\end{array}$ & $\begin{array}{l}\text { Quantidade de } \\
\text { Alunos }\end{array}$ \\
\hline Empresa A & Escola de Dança & Dança & 5 & 78 \\
\hline Empresa B & Academia & Musculação e Treinamento Funcional & 8 & 200 \\
\hline Empresa C & Estúdio de Pilates & Pilates & 1 & 82 \\
\hline Empresa D & Academia & $\begin{array}{c}\text { Musculação, Treinamento Funcional e } \\
\text { Yoga }\end{array}$ & 4 & 85 \\
\hline Empresa E & Academia & Musculação & 3 & 400 \\
\hline Empresa F & Academia & $\begin{array}{l}\text { Musculação, Treinamento Funcional, } \\
\text { Pilates e Crossfit }\end{array}$ & 2 & 60 \\
\hline Empresa G & Academia & Musculação, Pilates e Crossfit & 11 & 230 \\
\hline Empresa $\mathrm{H}$ & Estúdio de Pilates & Pilates & 1 & 60 \\
\hline Empresa I & Academia & Musculação e Yoga & 2 & 150 \\
\hline Empresa J & Estúdio de Pilates & Treinamento Funcional e Pilates & 1 & 34 \\
\hline
\end{tabular}

Fonte: Elaborado pelos autores

Observa-se que a maioria das empresas entrevistadas pertence ao ramo de academia, oferecendo com mais frequência as modalidades de musculação e pilates. As Organizações Esportivas entrevistadas caracterizam-se em empresas de pequeno porte com uma média de 150 alunos, podendo então justificar a quantidade baixa de funcionários. Com o intuito de confirmar quem são essas empresas, utilizou-se os estudos de Rezende (2000), que considera como Organizações Esportivas, academias voltadas para a atividade física e/ou esportiva, clubes e associações exclusivamente esportivos.

A partir das respostas das entrevistas, foi possível estabelecer um nível de prioridade das organizações para com as ofertas que são entregues aos consumidores. Desta forma, a pergunta para os gestores pretendeu identificar qual a principal preocupação das empresas na oferta dos serviços. As respostas foram condensadas no gráfico 1. Essa questão era conduzida para que o gestor entrevistado pudesse apresentar o nível de prioridade sobre os temas de atendimento ao cliente, profissionais qualificados, oferta de modalidade específica, preço ou condição de pagamento, disponibilidades de horário ou ambientes e equipamentos. 
As maiores preocupações dos gestores entrevistados consistem em oferecer um atendimento ao cliente através de profissionais qualificados. Soma-se a essas inquietações a de oferecer aos seus consumidores um bom ambiente, com equipamentos que consigam suprir as necessidades dos clientes e percebe-se um ponto importante sobre a venda de serviços, como o que fazem essas organizações. Mesmo os serviços sendo, em sua essência, uma oferta intangível, administrá-los recebe um olhar atento da academia. Lovelock e Wright (2006) em seus oito componentes da administração de serviços citam que o processo de atendimento, as pessoas envolvidas nesse processo e os sinais de evidências associados aos serviços, são elementos que devem ser administrados de forma clara e integrada para chegar ao sucesso perante os clientes (HILMANN, 2013).

Após esses pontos é que a variável preço ou condições de pagamento aparece. Isso pode ser reflexo da presença da lógica do serviço dominante (VARGO; LUSCH, 2004) onde o foco das empresas deve estar na oferta de serviços capazes de construir no cliente a percepção de que existe naquele momento - que pode ser uma prática esportiva - a co-criação de valor, o que por si só pode fazer o consumidor sentir que o preço despendido é justo na relação com o que é entregue.

É possível especular ainda que, ao investir mais na preparação do ambiente em que se presta o serviço, seja na forma de atendimento, com profissionais capacitados ou um bom maquinário, os gestores - mesmo sem perceber - estão construindo o que Cova e Dalli (2013) chama de linkng value. Os consumidores aproveitarão ao máximo a experiência conduzida pela organização esportiva, criando laços fortes com a instituição. Isso pode fazer com que os mesmos se tornem "working consumers" que advogam e muitas vezes trabalham pela marca a que estão ligados. Tudo isso pela grande experiência que é construída da relação organização/cliente.

Gráfico 1 - Nível de preocupação das Organizações Esportivas quanto à oferta de serviço

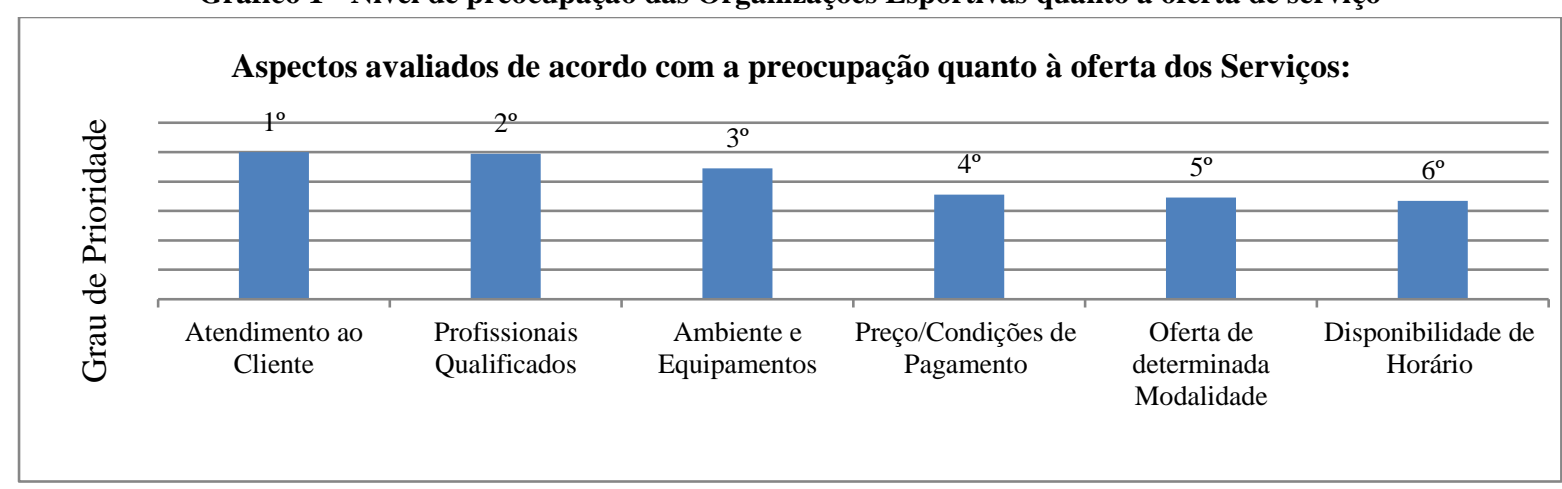

Fonte: Elaborado pelos autores

$\mathrm{Na}$ questão seguinte, pretendia-se estabelecer quais eram as atividades que as organizações praticavam em suas rotinas diárias. As repostas das entrevistas permitiram criar o gráfico 2. O resultado indicou que o relacionamento com o cliente é a atividade mais praticada pelos proprietários. Chama atenção esse fato, pois o marketing de relacionamento segundo Grönroos (2013) deve ser entendido como a gestão de uma promessa. Ao engajar-se em um relacionamento com o cliente, a organização estará criando um novo processo: o de cumprir e manter promessas feitas durante aquele consumo. E é precisamente isso que o autor defende. Que o relacionamento seja entendido como o gerenciamento das expectativas e experiências dos clientes na interação com a instituição.

Planejamento estratégico, controle de qualidade e pesquisa de mercado, também foram lembradas de forma mais significativa. Essas práticas podem ser consideradas esforços por parte das empresas para atingir de forma positiva seus clientes, o que corrobora com o pensamento de Grönroos (2013), quando este salienta o quanto os clientes de hoje são mais difíceis de agradar e manter um relacionamento. 
Considerando as atividades especificamente administrativas, ainda não praticadas pelas Organizações Esportivas, os resultados das entrevistas indicaram que gestão de finanças e investimentos (22\%) são atividades que os proprietários mais gostariam de praticar. Controle de qualidade (14\%), pesquisa de mercado (15\%) e planejamento estratégico (15\%) também merecem destaque. Os entrevistados mostraram pouco interesse em começar a praticar ou intensificar sua prática atual por aspectos como estratégia de vendas (12\%), relacionamento com o cliente (10\%), gestão de pessoas (7\%) e processos $(5 \%)$. Cabe ressaltar que algumas dessas atividades foram descritas como prioritárias por Parkhouse (2004) para um gestor esportivo, que acabam sendo deixadas para trás por parte dos gestores investigados nesse artigo.

Gráfico 2 - Percentuais de respostas quanto às atividades já praticadas pelas Organizações Esportivas

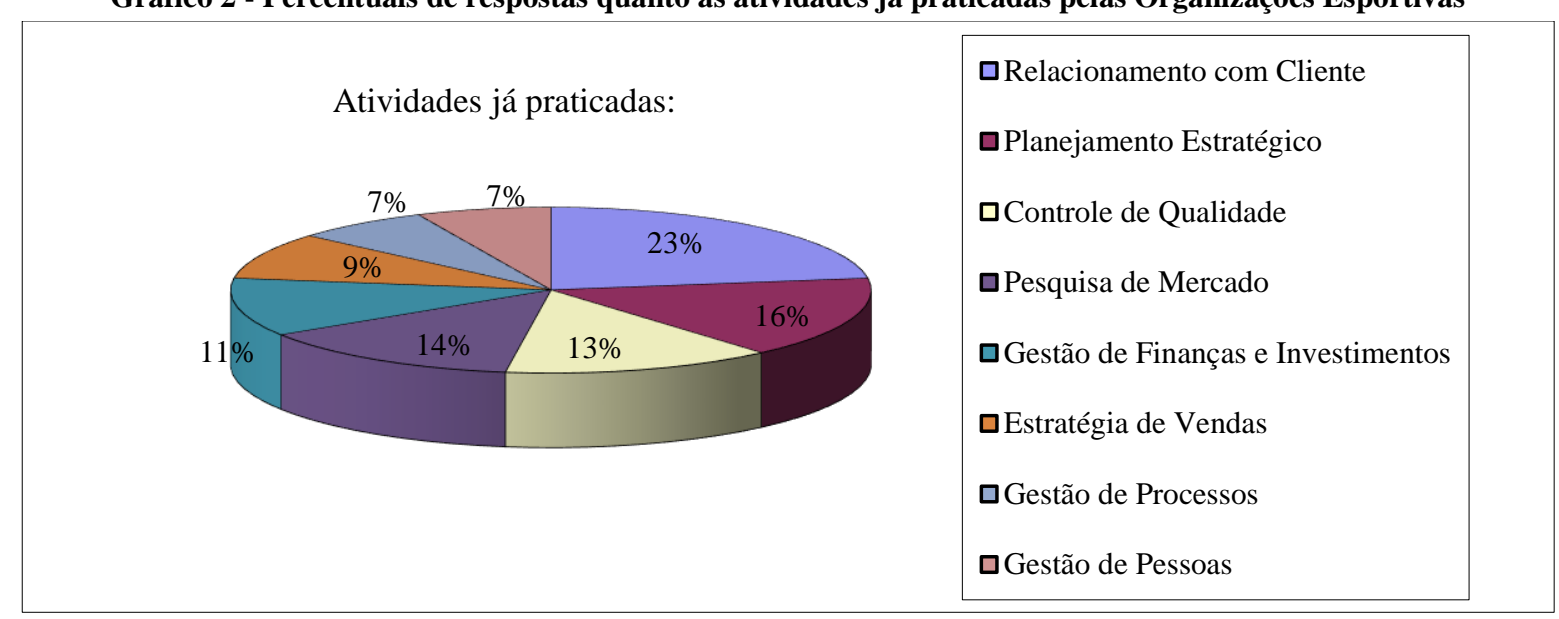

Fonte: Elaborado pelos autores

Quanto à responsabilidade sobre as atividades administrativas de cada empresa, constatou-se que essas são dos próprios proprietários, na grande maioria. Somente na realidade de uma Organização Esportiva (10\%) entrevistada, existe outro profissional à frente das atividades administrativas da empresa, tratando-se de um advogado. Em $70 \%$ dos casos os proprietários, com formação em Educação Física, são responsáveis por esta atividade, e em $20 \%$ das empresas trata-se do mesmo profissional de Educação Física, porém, com o apoio de outro profissional. Analisando os dados contidos nesse resultado, confirma-se a ideia de Saba (2006), quando esse autor diz que a função de gestão é muitas vezes exercida por professores de Educação Física, sem experiência administrativa. É necessário também trazer a opinião de Mazzei e Bastos (2012). Eles enfatizam que muitas habilidades são necessárias nos gestores que dirigem ou são proprietários de negócios esportivos, entre elas, estão os aspectos administrativos e de empreendedorismo.

Além disso, os entrevistados foram instigados a comentar sobre as necessidades que enfrentam no dia a dia da administração da sua empresa. Os apontamentos encontram-se no quadro 1. Os proprietários relatam dificuldades quanto à admissão de profissionais qualificados, o que pode remeter uma falta de conhecimento na área de recursos humanos. A afirmação nesse ponto é coerente com os achados relatados no começo dessa seção. Uma das principais preocupações dos gestores entrevistados consistia na busca por bons profissionais, capazes de auxiliar no desenvolvimento dos trabalhos. A busca por profissionais capacitados para auxiliar na condução de uma organização é importante, ainda mais no tocante às organizações de serviços, que têm nas pessoas o grande ponto de contato, para fomentar a co-criação de valor para o consumidor e fazê-lo se tornar um cliente em relacionamento. (VARGO; LUSCH, 2013; GRÖNROOS, 2013). 
Quadro 1 - Necessidades/carências enfrentadas no dia a dia das Organizações Esportivas

\begin{tabular}{|c|c|}
\hline \multicolumn{2}{|c|}{$\begin{array}{l}\text { Comente algumas necessidades/carências que você enfrenta no dia a dia da sua empresa referente às questões } \\
\text { administrativas: }\end{array}$} \\
\hline Empresa A & Tempo disponível para propaganda e marketing da escola. \\
\hline Empresa B & Aspectos da gestão da empresa e principalmente financeiros. \\
\hline Empresa C & Vários aspectos da administração, controle contábil, estratégia com clientes e marketing. \\
\hline Empresa D & Não existem necessidades, pois diante do conhecimento científico de um dos sócios estas são supridas. \\
\hline Empresa E & Encontrar profissionais de qualidade no mercado. \\
\hline Empresa F & Definição de custos e preços. \\
\hline Empresa G & Encontrar profissionais de qualidade no mercado. \\
\hline Empresa $\mathrm{H}$ & Definição de custos e preços e captação de alunos. \\
\hline Empresa I & Encontrar profissionais de qualidade no mercado \\
\hline Empresa J & Manter publicidade e captação de alunos. \\
\hline
\end{tabular}

Fonte: Elaborado pelos autores

Outros aspectos mencionados foram à dificuldade em administrar preços, custos e futuros investimentos, bem como ações de marketing, para captação e retenção de alunos. Uma forma interessante de observar esse resultado é retomar a formação dos proprietários, ou administradores, das organizações estudadas. A maioria das empresas é gerenciada por profissionais com formação no curso de Educação Física, que segundo Vieira e Stucchi (2007), não forma adequadamente seus alunos no que tange aos aspectos teóricos e práticos da gestão. Isso contribui negativamente para a formação dos gestores esportivos, que tendem a ser oriundos dos cursos de Educação Física e que clamam por qualificação profissional posterior (MOCSÁNYI; BASTOS, 2009; MELLO; SILVA, 2013). A qualificação dos profissionais envolvidos nas práticas de gestão esportiva, portanto, é imprescindível (MAZZEI; BASTOS, 2012).

Cruzando essas percepções, extraídas das análises de conteúdo das entrevistas, com as habilidades descritas por Parkhouse (2004), é possível perceber que alguns grupos de habilidades estão ausentes nos gestores investigados. A figura 1 apresenta tal cruzamento. As habilidades de marketing e vendas, capazes de buscar o cliente certo para a organização através de novas ideias, foram destacadas como necessárias por quatro gestores, das empresas A, C, H e J. Os aspectos financeiros, voltados ao fluxo de caixa, investimentos e capacidade de financiamento, foram citados pelos gestores das empresas B, C, F e H. Com três citações, os gestores das empresas E, G e I comentam sobre a necessidade de encontrar bons profissionais para trabalharem em sua organização, que são pertinentes às habilidades de recursos humanos. As habilidades básicas e de comunicação, voltadas à liderança, oratória para a criação de um discurso e prática claros, foram citadas pela empresa $\mathrm{C}$, que se apresentou o gestor com mais habilidades para serem desenvolvidas.

Figura 1 - Grupos de habilidades de Parkhouse (2004) e as empresas entrevistadas

\begin{tabular}{|c|c|c|}
\hline $\begin{array}{l}\text { Habilidades Básicas } \\
\text { - Empresa C }\end{array}$ & $\begin{array}{l}\text { Comunicação } \\
\text { • Empresa C }\end{array}$ & $\begin{array}{l}\text { Marketing e Vendas } \\
\text { - Empresa A } \\
\text { - Empresa C } \\
\text { - Empresa H } \\
\text { - Empresa J }\end{array}$ \\
\hline $\begin{array}{l}\text { Recursos Humanos } \\
\text { • Empresa E } \\
\text { • Empresa G } \\
\text { - Empresa I }\end{array}$ & Instalações esportivas & $\begin{array}{l}\text { Fiscais e Financeiros } \\
\text { - Empresa B } \\
\text { - Empresa C } \\
\text { - Empresa F } \\
\text { - Empresa H }\end{array}$ \\
\hline
\end{tabular}

Fonte: elaborado pelos os autores 
Diante da descrição das informações acima, nota-se que os proprietários enfrentam dificuldades quanto à admissão de profissionais qualificados, o que pode remeter uma falta de conhecimento na área de recursos humanos. Outros aspectos presentes foram à dificuldade em administrar preços, custos e futuros investimentos assim como ações de marketing na captação e retenção de alunos. É importante ressaltar e reforçar que as principais necessidades também se relacionam com a formação superficial em Administração Esportiva que as Universidades oferecem aos seus alunos. $\mathrm{O}$ teor dos cursos, suas disciplinas e métodos carecem de formação específica para o esporte (MAZZEI; AMAYA; BASTOS, 2013)

Esse problema de formação reforça os resultados encontrados nas entrevistas junto aos gestores. As habilidades a serem desenvolvidas pelos gestores analisados são prioritárias para Chelladurai (2009) e Rocha e Bastos (2011), no que tange à esfera da gestão esportiva. A coordenação das atividades de marketing, produção, recursos materiais e humanos são pontos importante para a manutenção das organizações e para a prestação de serviços de qualidade aos participantes e espectadores.

\section{CONSIDERAÇÕES FINAIS}

O presente trabalho pretendeu demonstrar como os gestores esportivos, tomando como análise um grupo de organizações de caráter esportivo, podem apresentar necessidades de desenvolvimento de habilidades extremamente importantes aos ocupantes de tal posição. O gestor esportivo é um profissional multidisciplinar, que deve ter o domínio de conteúdos variados, normalmente mesclando os conhecimentos técnicos da atividade, com os conhecimentos administrativos necessários para manter a organização com eficiência e eficácia.

O que se viu a partir desse trabalho, no entanto, é que muitas dessas organizações carecem de conhecimentos essenciais para o pleno funcionamento de uma empresa. Mesmo já praticando alguns pontos importantes, como o Relacionamento com os Clientes, muitas empresas não possuem à frente do seu negócio gestores com expertise financeira. Isso se reflete em dificuldades de administração, o que pode estar influenciando na criação de campanhas de comunicação e marketing mais assertivas e que tragam mais clientes a essas organizações. Tais pontos de melhoria requerem habilidades essenciais dos gestores esportivos, como demonstrado a partir da revisão de literatura exposta (CHELLADURAI, 2009; PARKHOUSE, 2004; MAZZEI; BASTOS, 2012).

O artigo tinha como objetivo analisar o contexto da cidade de Novo Hamburgo, no que se refere às Organizações Esportivas e as práticas já adotadas por seus gestores, além de suas necessidades de aprimoramento. O objetivo foi atingido, entretanto, houveram algumas limitações em seu desenvolvimento. $\mathrm{O}$ estudo teve um caráter qualitativo, com um número relativamente baixo de casos para analisar. Seguiu-se aqui uma linha de Eisenhardt (1989), com análises de quatro a dez casos, que tenham similaridades em um determinado ponto, mas diferenças em outros (LANGLEY; ABDALLAH, 2011). Mesmo seguindo essa diretriz, o resultado não é passível de generalização. Além desse ponto, a utilização de questionários estruturados para as entrevistas pode ter gerado um desperdício de dados que poderiam ser melhor coletados e analisados com outras técnicas de pesquisa qualitativa.

Ficam como sugestões de pesquisas futuras uma análise mais aprofundada dos currículos dos cursos em que os gestores esportivos se formaram, possibilitando assim confrontar as necessidades de desenvolvimento com as disciplinas ofertadas pelas Instituições de Ensino Superiores. Outro ponto pertinente para investigações futuras é o modo como as Organizações Esportivas concebem e utilizam o marketing de relacionamento de forma mais eficaz, uma vez que as empresas investigadas nesse artigo citaram a prática como atividade realizada. Além disso, indica-se para estudos futuros, uma exploração 
mais aprofundada sobre o marketing esportivo e o posicionamento do administrador nesta realidade, uma vez que o assunto abordado pode ser considerado relevante academicamente.

Com organizações esportivas posicionadas de forma eficaz no mercado, haverá maior interesse da população por atividades físicas diversas, resultando no valor e atenção aos benefícios do esporte na sociedade.

\section{REFERÊNCIAS}

AMARAL, C. M. S. O gestor do esporte no Brasil. Ensaios sobre gestão do esporte: reflexões e contribuições do GEPAE/EEFE-USP. São Paulo: OJM Casa Editorial, 2015.

; BASTOS, F. C. O gestor esportivo no brasil: revisão de publicações no país. Revista Intercontinental de Gestão Desportiva, Rio de Janeiro, v. 5, n. 1, p. 68-78, 2015.

BARDIN, L. Análise de conteúdo. 4. ed. PARIS: PUF, 2009.

BARROS FILHO, M. A. et al. Perfil do gestor esportivo brasileiro: uma revisão de literatura. Revista Intercontinental de Gestão Desportiva, Rio de Janeiro, v. 3, 2013.

BASTOS, F. C. et al. Perfil do administrador esportivo de clubes de São Paulo/Brasil. Revista Mackenzie de Educação Física e Esporte, São Paulo, v. 5, n. 1, p. 13-22, 2006.

BETTI, M. A Janela de vidro: esporte, televisão e educação física. Campinas, SP: Papirus, 1998.

CELMA, A. Aproximación al processo de La actuación deportiva y sus perspectivas de futuro. Anais do I Congresso de Gestión Deportiva de Cataluña. ACGEPG (Ed.). Zaragoza: Inde SA, 2000.

CHELLADURAI, P. Managing organizations for sport and physical activity: a systems perspective. Scottsdale: 3 ed. Holcomb Hathaway, 2009.

COVA, B.; DALLI, D. The Linking Value in Experiential Marketing: Acknowledging the Role of Working Consumers. In: MACLARAN; SAREN; STERN; TADAJEWSKI. The Sage Handbook of Marketing Theory. London: Sage, 2013.

DA COSTA, L. P. Conferência de Encerramento do I Congresso de Gestão Esportiva EEFEUSP, 2005. Transcrição. Disponível em: <https://docs.google.com/ document/d/1AOEcZnpfxsgzqsmCbVIPd_H0WoDGvtKI5Z2-Linl-E/edit>. Acesso em: 15 jan. 2017

EISENHARDT, K. M. Building theories from case study research. Academy of Management Review, New York, v. 14, n. 4, p. 532-550, 1989.

GASCA, D. G. Perspectivas de la Gestión Deportiva Municipal y Modelos de Gestión. In: Anais do I Congresso de Gestión Deportiva de Cataluña. ACGEPG (Ed.) (pp. 115-117). Zaragoza: Inde SA, 2000.

GAYA, A. (Org.). Ciências do movimento humano: introdução à metodologia da pesquisa. Porto Alegre: Artmed, 2008.

GIL, A. C. Como elaborar projetos de pesquisa. São Paulo, SP: Atlas, 2002. 175 p.

GRÖNROOS, C. Relationship Marketing as Promise Management. In: MACLARAN; SAREN; STERN; TADAJEWSKI. The Sage Handbook of Marketing Theory. London: Sage, 2013.

HANNAH, D. R.; LAUTSCH, B. A. Counting in qualitative research: Why to conduct it, when to avoid it, and when to closet it. Journal of Management Inquiry, v. 20, n.1, p. 14-22, 2011. 
HELAL, R. Passes e impasses: futebol e cultura de massa no Brasil. Petrópolis, RJ: Vozes, 1997.

HILLMANN, R. Administração de vendas, varejo e serviços. Curitiba: InterSaberes, 2013.

LANGLEY, A.; ABDALLAH, C. Templates and turns in qualitative studies of strategy and management. Research methodology in strategy and management, v. 6, p. 201-235, 2011.

LOVELOCK, C. WRIGHT, L. Serviços: marketing e Gestão. 6. Ed. São Paulo: Saraiva, 2006.

LUCENA, R. F. O esporte na cidade: aspectos do esforço civilizador brasileiro. Campinas, SP: Autores Associados, 2001. 152 p.

MASTERALEXIS, L.P.; BARR, C.A.; HUMS, M.A. Principles and practice of sport management. 3rd ed. Sudbury: Jones \& Bartlett, 2009.

MAZZEI, L. C.; AMAYA, K.; BASTOS, F. C. Programas acadêmicos de graduação em gestão do esporte no Brasil. Revista Mackenzie de Educação Física e Esporte, São Paulo, v. 12, n. 1, 2013.

MAZZEI, L. C.; BASTOS, Flávia da Cunha. Gestão do Esporte no Brasil: desafios e perspectivas. São Paulo, SP: Ícone, 2012.

MAZZEI, L. C.; OLIVEIRA, N. S.; ROCCO JUNIOR, A. J.; BASTOS, F. C. Uma análise da produção acadêmica brasileira em marketing esportivo enquanto área multidisciplinar. Revista Brasileira de Marketing, São Paulo, v.12, n.4, p. 183-200, 2013.

MELLO, J.A.C; SILVA, S.A.P.S. Competências do gestor de academias esportivas. Motriz, Rio Claro, v.19, n; 1, p.74-83, 2013.

MELO NETO, F. P. Marketing esportivo: o esporte como ferramenta do marketing moderno. Rio de Janeiro, RJ: Best Seller, 2013. 320 p.

MOCSÁNYI, V.; BASTOS, F.C. Gestão de pessoas na administração esportiva: considerações sobre os principais processos. Revista Mackenzie de Educação Física e Esporte, São Paulo, v. 4, n. 4, 2009.

MORGAN, M. J.; SUMMERS, J. Marketing Esportivo. São Paulo, SP: Thomson Learning, 2008. $422 \mathrm{p}$.

MULLIN, B.; HARDY, S.; SUTTON, W. Sport marketing. Illinois: Human Kinetics, 1993.

NOLASCO, V. P. et. al., Administração/Gestão Esportiva. In: COSTA, L. P. da (Org.). Atlas do esporte no Brasil: atlas do esporte, educação fisica e atividades físicas de saúde e lazer no Brasil. Rio de Janeiro: Shape, 2005. p. 760-761.

PARKHOUSE, B.L. The management of sport: its foundation and application. 4th ed. Boston: McGraw-Hill, 2004.

PARKS, J. B., ZANGER, B. K., QUARTERMAN, J. Contemporary Sport Management. Champaign, IL: Human Kinetics, 1998.

PIRES, G.; SARMENTO LOPES, P. S. R. Conceito de gestão do desporto, novos desafios, diferentes soluções. Revista Portuguesa de Ciências do Desporto, Porto, v. 1, n. 1, p. 88-103, 2001.

PRODANOV, C. C; FREITAS, E. C. Metodologia do Trabalho Científico: Métodos e Técnicas da Pesquisa e do Trabalho Acadêmico. Novo Hamburgo: Feevale, 2013. 276 p.

REZENDE, J. R. Organização e administração no esporte. Rio de Janeiro, RJ: Sprint, 2000. 198 p. 
ROCHA, C. M.; BASTOS, F. C. Gestão do esporte: definindo a área. Revista Brasileira de Educação Física e Esporte, São Paulo, v. 25, n. spe, p. 91-103, 2011.

SABA, F. Liderança e gestão: para academias e clubes esportivos. São Paulo, SP: Phorte, 2006. 181 p.

SBRIGHI, C. A. Como conseguir patrocínio esportivo: um plano para o sucesso no marketing esportivo. São Paulo, SP: Phorte, 2006. 79 p.

STEINHILBER, J. Profissional de educação física existe? Porque regulamentar a profissão. Rio de Janeiro: Sprint, 1996.

VARGO, S. L.; LUSCH, R. F. Evolving to a new dominant logic for marketing. Journal of Marketing, Chicago, v. 68, n. 1, p. 1-17, 2004.

A service-Dominant Logic for Marketing. In: MACLARAN; SAREN; STERN;

TADAJEWSKI. The Sage Handbook of Marketing Theory. London, Sage, 2013.

VELEZ, L.; BRAVO, G. Needs assessment in sport management education: exploring the Latin American market. North American Society Sport Management Conference Abstract Archive, Sport Management Conference (NASSM 2010) Tampa, Florida, jun. 1-5, p. 380-381, 2010. Disponível em: <http://www.nassm. com>. Acesso em: 10 jan. 2017.

VIEIRA T. P.; STUCCHI S. Relações preliminares entre a gestão esportiva e o profissional de educação física. Conexões, Campinas, v.5, n. 2, p. 113-128, 2007.

WOODSIDE, A. G.; WILSON, E. J. Case study research methods for theory building. Journal of Business \& Industrial Marketing, v. 18, n. 6/7, p. 493-508, 2003.

ZOUAIN, D. M.; PIMENTA, R. O perfil do gestor das organizações esportivas brasileiras. 2006. Disponível em: <http://www.educacaofisica.com.br/biblioteca_mostra.asp>. Acesso em: 01 abr. 2017. 